\title{
Lowering Cost Share May Improve Rates of Home Glucose Monitoring Among Patients with Diabetes Using Insulin
}

\author{
Yiqiong Xie, PhD; Abiy Agiro, PhD; Kevin Bowman, MD; and Andrea DeVries, PhD
}

\section{ABSTRACT}

BACKGROUND: Not much is known about the extent to which lower cost share for blood glucose strips is associated with persistent filling.

OBJECTIVE: To evaluate the relationship between cost sharing for blood glucose testing strips and continued use of testing strips.

METHODS: This is a retrospective observational study using medical and pharmacy claims data integrated with laboratory hemoglobin A1c (A1c) values for patients using insulin and blood glucose testing strips. Diabetic patients using insulin who had at least 1 fill of blood glucose testing strips between 2010 and 2012 were included. Patients were divided into a low cost-share group (out-of-pocket cost percentage of total testing strip costs over a 1-year period from the initial fill $<20 \% ; n=3,575$ ) and a high cost-share group (out-of-pocket cost percentage $\geq 20 \% ; n=3,580$ ). We compared the likelihood of continued testing strip fills after the initial fill between the 2 groups by using modified Poisson regression models.

RESULTS: Patients with low cost share had higher rates of continued testing strip fills compared with those with high cost share $(89 \%$ vs. $82 \%, P<0.001)$. Lower cost share was associated with greater probability of continued fills (adjusted risk ratio $[\mathrm{aRR}]=1.05,95 \% \mathrm{Cl}=1.03-1.07$, $P<0.001)$. Other patient characteristics associated with continued fills included type 1 diabetes diagnosis, types of insulin regimens, and health insurance plan type. In a subset analysis of patients whose A1c values at baseline were above the target level $(8 \%)$ set by the National Committee for Quality Assurance guidelines, we saw a slight increase in magnitude of relationship between cost share and continued fills $(R R=1.06,95 \%$ $\mathrm{Cl}=1.03-1.10, P<0.01)$.

CONCLUSIONS: There was a statistically significant association between cost share for testing strips and continued blood glucose self-monitoring. Among patients not achieving A1c control at baseline, there was an increase in the magnitude of relationship. Lowering cost share for testing strips can remove a barrier to persistence in diabetes self-management.

J Manag Care Spec Pharm. 2017;23(8):884-91

Copyright $\odot 2017$, Academy of Managed Care Pharmacy. All rights reserved.

\section{What is already known about this subject}

Financial burden has been identified as an important barrier to diabetes self-management practices, particularly the frequency of glucose self-monitoring.

Regular self-monitoring of glucose is more justified in diabetes patients using insulin due to evidence of improved hemoglobin Alc levels than in patients not using insulin.

Diabetic patients who do not meet Alc control targets are in greater need for more frequent self-monitoring of blood glucose.

\section{What this study adds}

This study quantified the relationship between cost sharing for blood glucose testing strips and continued dispensing of testing strips, particularly in the context of the level of glycemic control. Study findings suggested that cost sharing that falls below $20 \%$ of testing strip costs can facilitate persistent self-monitoring, especially among those not achieving glycemic control.

Payers and employers may consider including diabetes testing strips in lower cost-share tiers or informing members about preferred testing strips that are in the lower cost-share tiers.

S elf-monitoring of blood glucose (SMBG) is a key component of the care regimen for people with insulin-dependent diabetes. ${ }^{1-3}$ Guidelines from the American Diabetes Association (ADA), as well as from the American Association of Clinical Endocrinologists and the American College of Endocrinology, recommend SMBG at least 3 times daily for patients on high intensity insulin regimens and more often for those who do not meet glycemic goals. ${ }^{4-8}$ In practice, however, as many as $23 \%$ of people with insulin-dependent diabetes do not regularly monitor glucose levels. ${ }^{9}$

Literature dealing with possible reasons for the reduction or discontinuation of self-monitoring is sparse. In 1 study, patient perceptions of health professionals' attitudes seemed to affect self-monitoring, since it was found that some patients stopped self-monitoring because of their perceived disinterest on the part of health professionals in the meter readings provided by patients. ${ }^{10}$ Another study identified other reasons for SMBG reduction or discontinuation that included getting stable and predictable readings and increased awareness of bodily signs by participants. ${ }^{10}$ Conversely, reassurance and habit were found to be key reasons for the continuing of self-monitoring. ${ }^{10}$

Financial burden has also been identified as an important barrier to regular SMBG practices. In the United States, a large Kaiser Permanente study found that, among pharmacologically treated patients with type 1 or type 2 diabetes (with or without insulin use), the proportion of patients with daily SMBG and proportion of patients with $\geq 3$ times SMBG daily were lower in patients with higher out-of-pocket expenditures for glucometer strips than in patients with lower out-of-pocket costs, especially among those who were economically disadvantaged. ${ }^{11}$ As expected, a separate study among individuals 


\section{FIGURE 1 Sample Attrition}

Diabetic patients aged $18-75$ years who started testing strip fills between January 1, 2010, and December 31, 2012, with $\geq 1$ year continuous medical and pharmacy eligibilty before and after the initial testing strip fill. $\mathrm{N}=164,456$

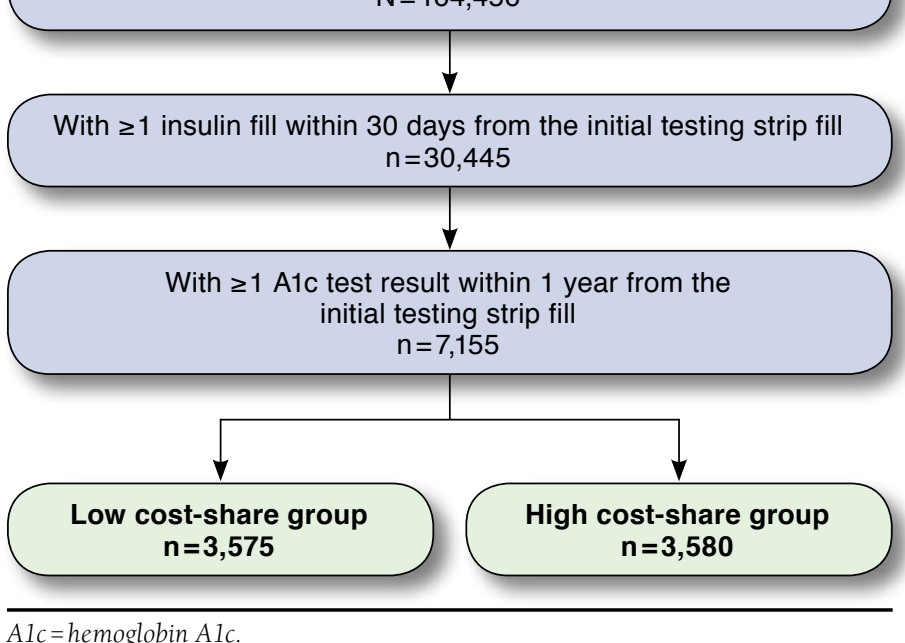

Alc $=$ hemoglobin Alc

with insulin-dependent diabetes found that those with lower household incomes spent a larger proportion of their income on medical supplies than those with higher incomes and so may have been less likely to monitor blood glucose levels. ${ }^{12}$ Out-of-pocket costs were also related to stopping or irregular self-monitoring among patients with diabetes in several international studies. ${ }^{13-16}$

The price of blood glucose testing strips ranges from around 20 cents per strip to as high as 2 dollars per strip, and insurance coverage and payment level vary according to benefit plan. ${ }^{17}$ For diabetic patients who are recommended to perform self-monitoring frequently (e.g., once per day or more), the total costs for 1 year can be high. Out-of-pocket cost for testing strips, as an added financial burden for diabetic patients who are typically on multiple medications, has been shown to be an important contributor to missed opportunities for the continued, regular use of testing strips. ${ }^{11-14}$ While intuitive, this is not universally accepted as a clear pathway for better diabetes management. For example, a large cross-sectional Canadian study reported that implementing quantity limits for reimbursement of blood glucose testing strips (i.e., limits of a maximum of 3,000 reimbursed strips for patients using insulin, 400 strips for patients on oral antidiabetic drugs at increased risk for hypoglycemia, and 200 strips for all other diabetic patients) was not related to worsening short-term clinical outcomes. ${ }^{18}$ This study, however, was limited because it did not examine the direct effect of this quantity-limit policy on patient self-monitoring practices. ${ }^{18}$
Our study was designed to evaluate the relationship between cost sharing and persistence with blood glucose testing strip fills among diabetic patients using insulin who had at least 1 testing strip fill. We limited the study population to those with insulin use because it has been suggested that SMBG is more justified in type 1 and type 2 diabetes patients using insulin for its beneficial effect on hemoglobin Alc (Alc) than in patients not using insulin. ${ }^{19}$ Furthermore, given the recommendation of more frequent self-monitoring for patients who do not meet glycemic goals, ${ }^{8,20}$ the relationship between cost share and continued testing strip fills was examined in a subset of patients not achieving glycemic control (i.e., Alc more than $8.0 \%$ as set by the National Committee for Quality Assurance guidelines) before initiating glucose monitoring using testing strips. Our primary hypothesis was that lower cost share was related to a higher likelihood of continued testing strip fills after the initial fill. The secondary hypothesis was that patients not meeting glycemic control targets will benefit more from lower cost share in terms of persistence with testing strip fills, since their need for SMBG is higher.

\section{Methods}

\section{Data Source}

Data were compiled from administrative medical and pharmacy claims obtained from the HealthCore Integrated Research Environment (HIRE). HIRE contains claims data for approximately 25 million Blue Cross Blue Shield health plan members across the United States. Researchers had access to a limited dataset with no patient identifiers. All study data were kept anonymous in full compliance with relevant provisions of the Health Insurance Portability and Accountability Act. Area median household income data were obtained by linking to the Area Health Resource File 2012-2013 based on ZIP codes of the areas in which the patients resided. ${ }^{21}$

This nonexperimental study, which was conducted under the research exception provisions of the Privacy Rule 45 CFR 164.514(e), was exempt from investigational review board review.

\section{Study Design and Population}

This retrospective observational study included commercially insured diabetic members aged 18-75 years who were new testing strip users and were using insulin.

Diabetes was defined as having $\geq 1$ medical claim with International Classification of Diseases, Ninth Revision, Clinical Modification diabetes diagnosis codes during the study period (see Appendix, available in online article). ${ }^{3}$ All patients had a blood glucose testing strip fill between January 1, 2010, and December 31, 2012, with no testing strip fills during the previous year, and all had continuous health plan enrollment for 1 year before and after the index date (i.e., the earliest blood glucose testing strip fill date during the study period). Patients were excluded if they had serious chronic conditions (coronary 
artery bypass surgery or percutaneous coronary intervention, ischemic vascular disease, thoracic aortic aneurysm, chronic heart failure, previous myocardial infarction, chronic renal failure, dementia, blindness, and amputation) according to the definitions from Healthcare Effectiveness Data and Information Set criteria. A total of 164,456 patients met this initial criteria. ${ }^{22}$

Among those patients meeting the previously mentioned criteria, insulin users were identified if they had at least 1 pharmacy claim for an insulin medication fill using Generic Product Identifier codes within 1 month from the index date ( $n=30,445$; see Appendix). ${ }^{3}$ Patients were also required to have at least 1 Alc testing result to assess the level of glycemic control in the year after the initial testing strip fill. A total of 7,155 patients met this criteria and comprised the final study sample (Figure 1).

For the second study hypothesis, we examined the relationship between cost share and subsequent testing strip fills in a subset of patients who did not meet the glycemic control goal in the year before the initial testing strip fill $(n=2,969)$.

\section{Study Group Assignment}

Patient cost share for blood glucose testing strips was calculated as the out-of-pocket cost percentage of total testing strip costs, created by dividing out-of-pocket costs by total testing strip costs and multiplying by $100 \%$. Out-of-pocket cost was the sum of copays, coinsurances, and deductibles paid by a patient over the 1-year period from the first testing strip fill. Total testing strip cost was the sum of out-of-pocket and health plan-paid amounts over the same period of time. We chose to use cost share percentages rather than dollar amounts because dollar amounts would be affected by adherence differences in addition to benefit design differences, since people with more testing fills (better adherence) are likely to pay more out-ofpocket than those with fewer fills (lower adherence).

Using the median cost share percentage (20\%) in our final sample, the study population was divided into 2 study groups: the low cost-share group (out-of-pocket cost percentage less than 20\%) and the high cost-share group (out-of-pocket cost percentage at or above $20 \%$ ). The study population was roughly split between these 2 groups (50\% low cost share and 50\% high cost share).

\section{Statistical Analysis}

Descriptive statistics including means ( \pm standard deviation [SD]) and frequencies were reported for continuous and categorical data, respectively. Differences in descriptive characteristics between the low versus high cost-share groups were assessed with t-tests for numeric data and Pearson's chi-square tests for categorical data.

The outcome of interest was continued use of blood glucose testing strips, defined as "at least 1 subsequent fill after the initial fill." The likelihood of patients with continued use in the low cost-share group was compared with that in the high cost-share group through relative risk (RR), which was estimated from the modified Poisson model with the associated standard errors obtained from the Sandwich method, ${ }^{23,24}$ taking into account age, gender, health insurance plan type (health maintenance organization [HMO]/preferred provider organization [PPO]/consumer-driven health plan [CDHP]), area median household income, type 1 diabetes status, types of insulin regimen, baseline oral antidiabetic (OAD) dispensing, baseline diabetic adverse events (hypoglycemia/ ketoacidosis), Deyo-Charlson Comorbidity Index (DCI), baseline medications for metabolic disorder, cost share for all prescription claims, and cost share for all medical claims.

The association between cost share and continued use of testing strips was then examined in the subset of patients not meeting glycemic control, in order to evaluate the association in the context of patient glycemic levels.

All statistical analyses were conducted with SAS 9.4 software for Windows (SAS Institute, Cary, NC). Alpha was set at 0.05.

\section{Results}

\section{Patient Characteristics}

The analysis comprised 7,155 patients $(3,575$ in the low costshare group and 3,580 in the high-cost share group; Table 1). Patient demographic and clinical characteristics were compared between the 2 groups to examine any differences in baseline profile. Compared with the low cost-share group, those in the high cost-share group were slightly older (low cost share: 49 years; high cost share: 50 years; $P<0.01$ ) and had a lower area median household income (low cost share: $\$ 56,686$; high cost share: $\$ 52,872 ; P<0.001)$. The most common comorbid conditions in both groups were dyslipidemia (low cost share: 58.8\%; high cost share: $60.3 \% ; P=0.22$ ) and hypertension (low cost share: $57.2 \%$; high cost share: $60.3 \% ; P=0.01$ ). Proportions of patients with baseline fills of medications for metabolic disorders (i.e., cardiovascular disease, dyslipidemia, or hypertension) and OAD medications were higher in the high cost-share group than in the low cost-share group (medications for metabolic disorders: $74.9 \%$ high vs. $72.1 \%$ low cost share, $P<0.05$; OADs: $57.4 \%$ high vs. $48.6 \%$ low cost share, $P<0.001$ ). The DCI score and proportion of patients on a basal-only regimen were lower among patients with high cost share than among those with low cost share (1.8 vs. $2.0, P<0.001$, and $34.6 \%$ vs. $22.5 \%, P<0.001$, respectively; Table 1 ).

The median out-of-pocket cost share of total testing strips in the 1-year follow-up period was $9 \%$ and $29 \%$ in the low costshare and high cost-share groups, respectively. Mean out-ofpocket costs were $\$ 89$ and $\$ 225$ in the low and high cost-share groups, respectively $(P<0.001)$. As expected, total prescription cost share and medical cost share during the 1-year follow-up were lower in the low cost-share group (mean 20\% prescription, $21 \%$ medical) than in the high cost-share group (mean 
TABLE 1 Baseline Demographic and Clinical Characteristics of Diabetic Patients on Insulin Using Blood Glucose Testing Strips

\begin{tabular}{|c|c|c|c|c|c|}
\hline & \multicolumn{5}{|c|}{ Users of Insulin } \\
\hline & \multicolumn{2}{|c|}{$\begin{array}{l}\text { Low Cost Share } \\
\quad(\mathbf{n}=3,575)\end{array}$} & \multicolumn{2}{|c|}{$\begin{array}{l}\text { High Cost Share } \\
(\mathrm{n}=3,580)\end{array}$} & $P$ Value ${ }^{a}$ \\
\hline \multicolumn{6}{|l|}{ Demographic characteristics } \\
\hline Age (on index date), mean (SD) & 49 & $(12.7)$ & 50 & (11.2) & $<0.010$ \\
\hline Age category, $\mathrm{n}(\%)$ & & & & & $<0.001$ \\
\hline $18-44$ & 1,172 & $(32.8)$ & 986 & $(27.5)$ & \\
\hline $45-64$ & 2,098 & $(58.7)$ & 2,408 & $(67.3)$ & \\
\hline $65-75$ & 305 & $(8.5)$ & 186 & $(5.2)$ & \\
\hline Gender, n (\%) & & & & & 0.490 \\
\hline Female & 1,675 & $(46.9)$ & 1,648 & $(46.0)$ & \\
\hline Male & 1,900 & $(53.1)$ & 1,932 & $(54.0)$ & \\
\hline Plan type, n (\%) & & & & & $<0.001$ \\
\hline $\mathrm{HMO}$ & 1,275 & $(35.7)$ & 1,433 & $(40.0)$ & \\
\hline $\mathrm{PPO}$ & 2,129 & $(59.6)$ & 1,853 & $(51.8)$ & \\
\hline CDHP & 171 & $(4.8)$ & 294 & $(8.2)$ & \\
\hline Area median household income, \$, mean (SD) & 56,686 & $(14,351.99)$ & 52,872 & $(13,929.44)$ & $<0.001$ \\
\hline Area median household income category, n (\%) & & & & & $<0.001$ \\
\hline$\$ 0-\$ 39,999$ & 351 & $(9.8)$ & 549 & $(15.3)$ & \\
\hline$\$ 40,000-\$ 59,999$ & 1,801 & $(50.4)$ & 1,857 & $(51.9)$ & \\
\hline$\$ 60,000-\$ 79,999$ & 990 & $(27.7)$ & 833 & $(23.3)$ & \\
\hline$\geq \$ 80,000$ & 207 & $(5.8)$ & 163 & $(4.6)$ & \\
\hline Unknown & 226 & $(6.3)$ & 178 & $(5.0)$ & \\
\hline \multicolumn{6}{|l|}{ Clinical characteristics } \\
\hline DCI & 2.0 & $(1.6)$ & 1.8 & $(1.4)$ & $<0.001$ \\
\hline Type 1 diabetes diagnosis, $\mathrm{n}(\%)$ & 352 & $(9.8)$ & 251 & $(7.0)$ & $<0.001$ \\
\hline Type of insulin regimen, $\mathrm{n}(\%)$ & & & & & $<0.001$ \\
\hline Basal only & 806 & $(22.5)$ & 1,239 & $(34.6)$ & \\
\hline Bolus use only & 671 & $(18.8)$ & 317 & $(8.9)$ & \\
\hline Premixed use only & 149 & $(4.2)$ & 208 & $(5.8)$ & \\
\hline Basal and bolus use only & 1,773 & $(49.6)$ & 1,540 & $(43.0)$ & \\
\hline Other insulin/combination & 176 & $(4.9)$ & 276 & $(7.7)$ & \\
\hline \multicolumn{6}{|l|}{ Comorbid conditions, $\mathrm{n}(\%)$} \\
\hline Dyslipidemia & 2,103 & $(58.8)$ & 2,157 & $(60.3)$ & 0.220 \\
\hline Hypertension & 2,045 & $(57.2)$ & 2,158 & $(60.3)$ & 0.010 \\
\hline Renal disease & 202 & $(5.7)$ & 146 & $(4.1)$ & $<0.001$ \\
\hline Fill for metabolic disorder medication, ${ }^{\mathrm{b}} \mathrm{n}(\%)$ & 2,579 & $(72.1)$ & 2,682 & $(74.9)$ & 0.010 \\
\hline Fill for OAD medications, $\mathrm{n}(\%)$ & 1,737 & $(48.6)$ & 2,055 & $(57.4)$ & $<0.001$ \\
\hline Diabetic adverse events, $\mathrm{n}(\%)$ & 323 & $(9.0)$ & 293 & $(8.2)$ & 0.200 \\
\hline \multicolumn{6}{|l|}{ Cost of total testing strips, ${ }^{\mathrm{c}} \$$} \\
\hline Out-of-pocket amounts, \$, mean (SD) & 89 & $(114.69)$ & 225 & $(250.84)$ & $<0.001$ \\
\hline Median, $\%$ & & 3 & & 56 & \\
\hline Health plan-paid amounts, \$, mean (SD) & 1,058 & $(890.17)$ & 439 & $(448.41)$ & $<0.001$ \\
\hline Median, \% & & 17 & & 92 & \\
\hline Out-of-pocket cost-share percentage, mean (SD) & 8 & $(6.89)$ & 37 & $(19.02)$ & $<0.001$ \\
\hline Median, \% & & 9 & & 9 & \\
\hline \multicolumn{6}{|c|}{ Cost-share percentage for all pharmacy claims ${ }^{\mathrm{d}}(\mathrm{n}=7,026)$} \\
\hline Mean (SD) & 20.14 & $(16.32)$ & 31.61 & $(20.63)$ & $<0.001$ \\
\hline Median, \% & & .22 & & 56 & \\
\hline \multicolumn{6}{|c|}{ Cost-share percentage for all medical claims ${ }^{\mathrm{d}}(\mathrm{n}=7,072)$} \\
\hline Mean (SD) & 21.31 & $(18.6)$ & 29.45 & $(22.03)$ & $<0.001$ \\
\hline Median, \% & & .29 & & 68 & \\
\hline \multicolumn{6}{|c|}{$\begin{array}{l}\text { aP values were derived from chi-square tests for categorical variables and t-tests for continuous variables. } \\
\text { b One or more medications for treatment of cardiovascular disease, dyslipidemia, or hypertension. } \\
\text { cIn 1-year period following initial testing strip fill. } \\
\text { dVariable had missing values when division by zero occurred (i.e., when products were provided with no plan and patient-paid amounts). } \\
\text { CDHP = consumer-driven health plan; DCI=Deyo-Charlson Comorbidity Index; HMO=health maintenance organization; OAD=oral antidiabetic; PPO=preferred } \\
\text { provider organization; } S D=\text { standard deviation. }\end{array}$} \\
\hline
\end{tabular}




\begin{tabular}{|c|c|c|c|}
\hline $\begin{array}{l}\text { Desc } \\
\text { Bloo } \\
\text { Patie } \\
\text { Duri } \\
\text { Testi }\end{array}$ & \multicolumn{3}{|c|}{$\begin{array}{l}\text { Descriptive Statistics for Subsequent } \\
\text { Blood Glucose Testing Strip Use Among } \\
\text { Patients with Diabetes on Insulin } \\
\text { During } 12 \text { Months After Initiating } \\
\text { Testing Strip Fill }\end{array}$} \\
\hline & \multicolumn{3}{|c|}{ Users of Insulin } \\
\hline & $\begin{array}{c}\text { Low-Cost Share } \\
(\mathbf{n}=3,575)\end{array}$ & $\begin{array}{c}\text { High-Cost Share } \\
(\mathbf{n}=3,580)\end{array}$ & $\begin{array}{c}P \\
\text { Value }^{\mathrm{a}} \\
\end{array}$ \\
\hline \multicolumn{3}{|c|}{ Subsequent testing strip fills, $\mathrm{n}(\%)$} & $<0.001$ \\
\hline 0 fill & $(10.9)$ & $(17.7)$ & \\
\hline 1 fills & $(12.9)$ & $(15.1)$ & \\
\hline 2 fills & $(11.0)$ & $(12.0)$ & \\
\hline$\geq 3$ fills & $2,330 \quad(65.2)$ & $1,974 \quad(55.1)$ & \\
\hline \multicolumn{4}{|c|}{ Average number of subsequent testing strip fills, mean (SD) } \\
\hline Among all patients & $4.7 \quad(3.8)$ & $4.0 \quad(3.8)$ & $<0.001$ \\
\hline $\begin{array}{l}\text { Among patients with } \geq 1 \\
\text { subsequent fill }\end{array}$ & $(3.6)$ & $(3.6)$ & $<0.001$ \\
\hline $\begin{array}{l}\text { Number of days of supply } \\
\text { per fill, mean (SD) }\end{array}$ & $(34.1)$ & $(23.9)$ & $<0.001$ \\
\hline Median & 20.5 & 20.0 & \\
\hline \multicolumn{4}{|c|}{$\begin{array}{l}\text { a v values were derived from chi-square tests for categorical variables and t-tests for } \\
\text { continuous variables. } \\
S D=\text { standard deviation. }\end{array}$} \\
\hline
\end{tabular}

$32 \%$ prescription, $29 \%$ medical, both with $P<0.001$, compared with the low cost-share group; Table 1).

\section{Glucose Test Strip Use}

Overall, $86 \%$ patients had at least 1 subsequent testing strip fill after the initial fill, including 14\% with 1 subsequent fill, 12\% with 2 subsequent fills, and $60 \%$ with 3 or more subsequent fills.

The proportion of patients who continued the use of testing strips was higher in the low cost-share group (89\%) than in the high cost-share group $(82 \% ; P<0.001)$. Among those with at least 1 subsequent testing strip fill, the mean number of subsequent fills was greater in the low cost-share group than in the high costshare group (5.3 vs. 4.8 , respectively, $P<0.001$; Table 2 ).

In the subset of patients who did not achieve glycemic control goal at baseline, there is a similar pattern of more subsequent fills in the lower cost-share group (Figure 2).

\section{Multivariable Analysis}

After controlling for key factors, patients with low cost-share for testing strips were more likely to continue testing strip fills after the initial fill, compared with the high cost-share group (RR=1.05; 95\% confidence interval $[\mathrm{CI}]=1.03-1.07 ; \mathrm{P}<0.001$; Table 3). Patients with type 1 diabetes were more likely to continue testing strip fills than those without $(\mathrm{RR}=1.03,95 \%$ $\mathrm{CI}=1.00-1.06, P=0.02$ ). Patients on a bolus only regimen or a basal and bolus only regimen were more likely to continue fills than those on basal only $(\mathrm{RR}=1.15,95 \% \mathrm{CI}=1.11-1.19$ and $\mathrm{RR}=1.15,95 \% \mathrm{CI}=1.12-1.19, \mathrm{P}<0.001$, respectively). Patients
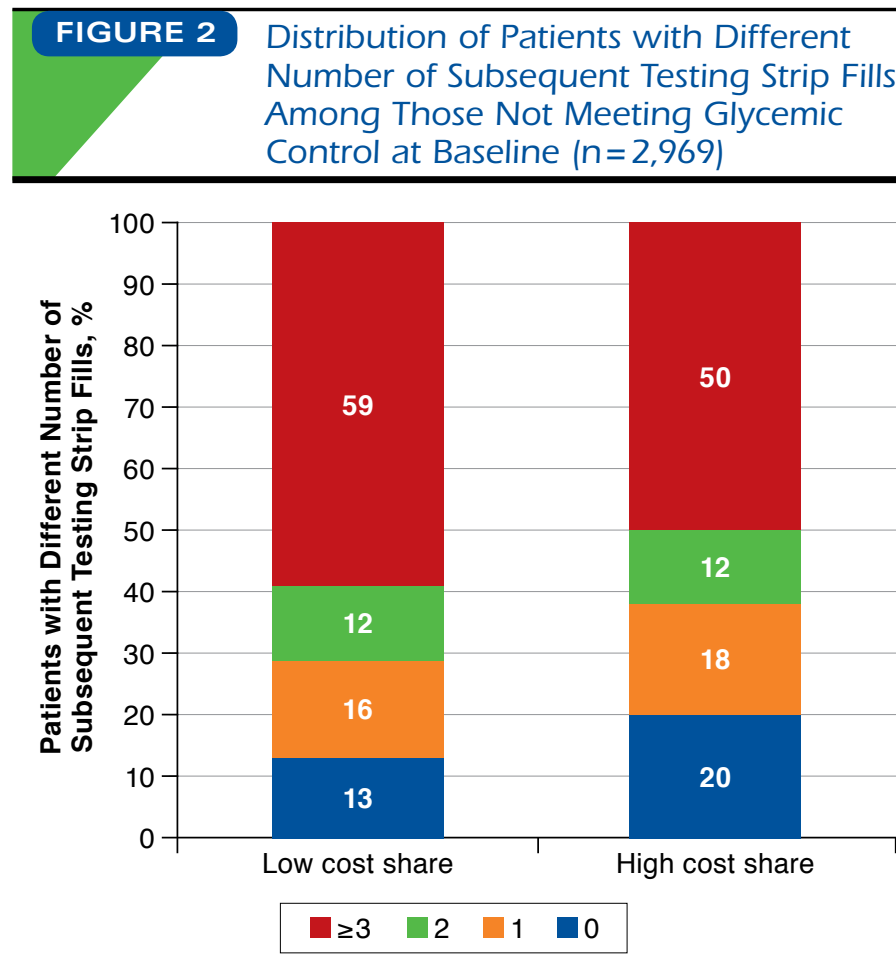

in PPO or CDHP plans were also more likely to continue fills than those with HMO plans ( $\mathrm{RR}=1.03,95 \% \mathrm{CI}=1.01-1.06$ and $\mathrm{RR}=1.08,95 \% \mathrm{CI}=1.04-1.12, \mathrm{P}<0.01$, respectively).

Among patients who did not meet glycemic control goal before the initial testing strip fill, we observed that lower cost sharing was related to a higher likelihood of continued fills ( $\mathrm{RR}=1.06,95 \% \mathrm{CI}=1.03-1.10, \mathrm{P}<0.01)$.

\section{Discussion}

This real-world observational study demonstrated that among our patient population, the cohort with lower cost share for blood glucose testing strips was more likely to continue use of testing strips and also had more total fills than patients who had higher cost share. We chose to use a dichotomous median cost-share grouping, since this allows for balanced comparison groups of nearly equal sample sizes, and the measure of association of RR from the comparison of 2 groups is easy to interpret. Meanwhile, we conducted a sensitivity analysis by categorizing the study sample into 4 groups using quartiles of cost-share percentage and found that the proportions of patients having subsequent fills were $89 \%, 89 \%, 83 \%$, and $81 \%$ in the 4 groups of lowest to highest cost share, respectively. This is consistent with our conclusion that lower cost share was related to higher likelihood of the continued dispensing of testing strips. 


\section{TABLE 3 Modified Poisson Regression Modeling Probability of Having Subsequent Testing Strip Fills}

\begin{tabular}{|c|c|c|c|}
\hline & \multicolumn{3}{|c|}{ Diabetic Insulin Users $(\mathrm{N}=7,155)$} \\
\hline & aRR & $95 \% \mathrm{CI}$ & $P$ Value \\
\hline Low cost share vs. high cost share & 1.05 & $1.03-1.07$ & $<0.0001$ \\
\hline Aged $45-64$ years vs. $18-44$ years & 1.02 & $1.00-1.05$ & 0.0700 \\
\hline Aged $65-75$ years vs. $18-44$ years & 1.04 & $1.00-1.09$ & \\
\hline Female vs. male & 1.01 & $0.99-1.03$ & 0.4300 \\
\hline Income: $\$ 40,000-\$ 60,000$ vs. $\$ 0-\$ 40,000$ & 1.02 & $0.98-1.05$ & 0.5100 \\
\hline Income: $\$ 60,000-\$ 80,000$ vs. $\$ 0-\$ 40,000$ & 1.00 & $0.97-1.04$ & \\
\hline Income: $\geq \$ 80,000$ vs. $\$ 0-\$ 40,000$ & 0.99 & $0.94-1.04$ & \\
\hline Type 1 diabetes diagnosis: yes vs. no & 1.03 & $1.00-1.06$ & 0.0200 \\
\hline Baseline OAD medications: yes vs. no & 0.98 & $0.96-1.00$ & 0.0400 \\
\hline Baseline diabetic adverse events: yes vs. no & 1.01 & $0.98-1.05$ & 0.4100 \\
\hline Baseline chronic condition medications: yes vs. no & 1.00 & $0.98-1.03$ & 0.7200 \\
\hline Baseline cost share for all pharmacy claims (continuous) & 1.00 & $1.00-1.00$ & 0.7800 \\
\hline Baseline cost share for all medical claims (continuous) & 1.00 & $1.00-1.00$ & 0.8800 \\
\hline Types of insulin regimen (reference: basal only) & & & $<0.0001$ \\
\hline Bolus only & 1.15 & $1.11-1.19$ & \\
\hline Premixed only & 1.05 & $0.99-1.11$ & \\
\hline Basal and bolus only & 1.15 & $1.12-1.19$ & \\
\hline Other & 1.03 & $0.97-1.09$ & \\
\hline Plan type: PPO vs. HMO & 1.03 & $1.01-1.06$ & $<0.0100$ \\
\hline Plan type: CDHP vs. HMO & 1.08 & $1.04-1.12$ & \\
\hline DCI (continuous) & 1.01 & $1.00-1.01$ & 0.1200 \\
\hline
\end{tabular}

aRR = adjusted risk ratio; $C D H P=$ consumer-driven health plan; $C I=$ confidence interval; $H M P=$ health maintenance organization; $O A D=$ oral antidiabetic;

$\mathrm{PPO}=$ preferred provider organization .

Most existing literature on discontinuation of self-monitoring through use of testing strips included patients who were not using insulin, had relatively small sample sizes, and were from countries other than the United States. ${ }^{10,13,25}$ Our study was conducted among a large population of diabetic patients in the United States who were using insulin. Previous studies of the effect of financial burden on diabetes management largely focused on the frequency of self-monitoring (and showed a negative effect of financial burden on self-monitoring), ${ }^{11,12,14}$ while our study focused on the continued dispensing of testing strips after the initial fill. Given the paucity of studies on patient persistence in blood glucose self-monitoring, our findings contributed new evidence that financial burden is a barrier to SMBG practices.

A strength of this study is that the association of cost share and self-monitoring was examined in a subset of patients who did not meet glycemic control before the initial testing strip fill. We found that the association in this subset of patients was slightly stronger than that among the entire cohort. This finding has clinical importance, since patients not meeting glycemic target levels are encouraged to perform self-testing more frequently. ${ }^{7,8}$ In this study population, we also found that continued use of testing strips were related to a higher likelihood of glycemic control. ${ }^{26}$ Accordingly, these patients may benefit to a larger extent from any actions or programs that promote continued testing strip use.

An encouraging finding from our study was that those in greater need of consistent glucose monitoring (i.e., with a type 1 diabetes diagnosis, or on bolus only or basal and bolus only regimens vs. basal only) were more likely to have continued use of testing strips. This is consistent with the ADA's recommendation that SMBG be performed more frequently in patients on highly intensive insulin regimens that includes multiple insulin injections. ${ }^{7}$

Our study found that lower cost share was related to a higher likelihood of continued blood glucose self-monitoring and that the association remained statistically significant after adjusting for relevant patient characteristics. The findings suggested that cost sharing that falls below 20\% of testing strip costs can facilitate persistent self-monitoring, particularly among those not achieving glycemic control. Based on this finding, payers and employer groups may consider including diabetes testing strips in lower cost-share tiers (e.g., coverage by Medicare Part B of glucose testing strips as durable medical equipment and Anthem's benefit designs that include coverage for glucose testing strips) or communicating to members the preferred testing strips that are in the lower cost-share tiers. One way to make sure patients get the right testing strips is for providers to ensure that the glucose meters prescribed to 
patients are compatible with the testing strips covered under the lowest tier formulary of patient health plans. Patients may also be encouraged to seek out glucose monitoring kits that use the lower cost testing strips.

\section{Limitations}

This study has several limitations to be considered. First, pharmacy fills do not necessarily confirm actual use of dispensed testing strips, so the relationship between cost share and actual continued testing may be overestimated. In addition, there can be different days of supply related to each fill, and in this study, no threshold in number of days was used to define a fill to be included. We found that, on average, each fill was for around 29 and 25 days of supply in low and high cost-share groups, respectively.

Second, the patients included in this study were from a single large commercial insurer, which may not be representative of all insulin-using patients who use blood glucose testing strips. A population of commercially insured individuals also results in a cohort that is younger and healthier than the overall population with diabetes. Although findings regarding an association between age and frequency of SMBG have been inconsistent, the presence of fewer comorbidities has been related to reduced SMBG. ${ }^{11,14,27}$ Finally, patients may have obtained blood glucose testing strips through sources other than their health plans (e.g., from over-the-counter purchases). The fact that this sample had at least 1 first fill partly helps to alleviate this concern.

\section{Conclusions}

Diabetic patients using insulin were more likely to continue use of testing strips when they had a lower level of cost sharing. Lowering cost sharing for testing strips can remove a barrier to persistence of diabetes self-management.

\section{Authors}

YIQIONG XIE, PhD; ABIY AGIRO, PhD; and ANDREA DEVRIES, $\mathrm{PhD}$, HealthCore, Wilmington, Delaware. KEVIN BOWMAN, MD, Anthem, Indianapolis, Indiana.

AUTHOR CORRESPONDENCE: Abiy Agiro, PhD, HealthCore, 123 Justison St., Ste. 200, Wilmington, DE 19801

Tel.: 302.230.2185; E-mail: aagiro@healthcore.com.

\section{DISCLOSURES}

Funding for this study was provided by Anthem, which had no role in the study design, data interpretation, or preparation or review of the manuscript. The decision to publish was strictly that of the authors. Xie, Agiro, and DeVries are employees of HealthCore, a wholly owned subsidiary of Anthem. Bowman is an employee of Anthem.
Study concept and design were contributed by all the authors. Xie took the lead in data collection, along with Agiro, and data interpretation was performed by all the authors. The manuscript was written by Xie and Agiro, along with DeVries, and revised by Xie, Agiro, and Devries, along with Bowman.

\section{ACKNOWLEDGMENTS}

The authors thank David (Marc) Cram, senior research programmer at HealthCore, who conducted programming for this study, and Cheryl Jones, senior medical writer at HealthCore, for editorial assistance.

\section{REFERENCES}

1. Martin S, Schneider B, Heinemann L, et al. Self-monitoring of blood glucose in type 2 diabetes and long-term outcome: an epidemiological cohort study. Diabetologia. 2006;49(2):271-78.

2. Nyomba BL, Berard L, Murphy LJ. Facilitating access to glucometer reagents increases blood glucose self-monitoring frequency and improves glycaemic control: a prospective study in insulin-treated diabetic patients. Diabet Med. 2004;21(2):129-35.

3. Yeaw J, Lee WC, Aagren M, Christensen T. Cost of self-monitoring of blood glucose in the United States among patients on an insulin regimen for diabetes. J Manag Care Pharm. 2012;18(1):21-32. Available at: http://www. jmcp.org/doi/10.18553/jmcp.2012.18.1.21.

4. Canadian Diabetes Association, Clinical Practice Guidelines Expert Committee. Canadian Diabetes Association 2013 clinical practice guidelines for the prevention and management of diabetes in Canada. Can J Diabetes. 2013;37(Suppl 1):S1-S216.

5. Handelsman Y, Bloomgarden ZT, Grunberger G, et al. American Association of Clinical Endocrinologists and American College of Endocrinology—clinical practice guidelines for developing a diabetes mellitus comprehensive care plan-2015. Endocr Pract. 2015;21(Suppl 1):1-87.

6. International Diabetes Federation. 2011 guideline for management of postmeal glucose. Available at: https://www.idf.org/our-activities/advocacyawareness/resources-and-tools/82:management-of-postmeal-glucose.html. Accessed June 6, 2017.

7. American Diabetes Association. Standards of medical care in diabetes-2017. Diabetes Care. 2017;40(Suppl 1):S4-S5.

8. Garber AJ, Abrahamson MJ, Barzilay JI, et al. AACE/ACE comprehensive diabetes management algorithm 2015. Endocr Pract. 2015;21(4):438-47.

9. Centers for Disease Control and Prevention. Self-monitoring of blood glucose among adults with diabetes-United States, 1997-2006. MMWR Morb Mortal Wkly Rep. 2007;56(43):1133-37.

10. Peel E, Douglas M, Lawton J. Self monitoring of blood glucose in type 2 diabetes: longitudinal qualitative study of patients' perspectives. BMJ. 2007;335(7618):493.

11. Karter AJ, Ferrara A, Darbinian JA, Ackerson LM, Selby JV. Selfmonitoring of blood glucose: language and financial barriers in a managed care population with diabetes. Diabetes Care. 2000;23(4):477-83.

12. Songer TJ, DeBerry K, LaPorte RE, Tuomilehto J. International comparisons of IDDM mortality. Clues to prevention and the role of diabetes care. Diabetes Care. 1992;15(Suppl 1):15-21.

13. Simmons D, Peng A, Cecil A, Gatland B. The personal costs of diabetes: a significant barrier to care in South Auckland. N Z Med J. 1999;112(1097):383-85.

14. Ong WM, Chua SS, Ng CJ. Barriers and facilitators to self-monitoring of blood glucose in people with type 2 diabetes using insulin: a qualitative study. Patient Prefer Adherence. 2014;8:237-46.

15. Bowker SL, Mitchell CG, Majumdar SR, Toth EL, Johnson JA. Lack of insurance coverage for testing supplies is associated with poorer glycemic control in patients with type 2 diabetes. CMAJ. 2004;171(1):39-43. 
16. Shakibazadeh E, Larijani B, Shojaeezadeh D, Rashidian A, Forouzanfar M, Bartholomew L. Patients' perspectives on factors that influence diabetes selfcare. Iran J Public Health. 2011;40(4):146-58.

17. Spero D. Why do test strips cost so much? Diabetes Self-Management blog. September 18, 2013. Available at: https://www.diabetesselfmanagement.com/blog/why-do-test-strips-cost-so-much/. Accessed June 6, 2017.

18. Gomes T, Martins D, Tadrous M, et al. Association of a blood glucose test strip quantity-limit policy with patient outcomes: a population-based study. JAMA Intern Med. 2017;177(1):61-66.

19. Malanda UL, Bot SD, Nijpels G. Self-monitoring of blood glucose in noninsulin-using type 2 diabetic patients: it is time to face the evidence. Diabetes Care. 2013;36(1):176-78.

20. American Diabetes Association. Standards of medical care in diabetes-2015. Diabetes Care. 2015;38(Suppl 1):1-89. Available at: http://care diabetesjournals.org/content/38/Supplement_l. Accessed June 6, 2017.

21. Health Resources and Services Administration. Data Warehouse. Area Health Resource File (AHRF) 2012-2013. Available at: https://datawarehouse.hrsa.gov/topics/ahrf.aspx. Accessed June 6, 2017.
22. National Committee for Quality Assurance. Comprehensive diabetes care. HEDIS measure of care. Available at: http://www.ncqa.org/reportcards/health-plans/state-of-health-care-quality/2016-table-of-contents/ diabetes-care. Accessed June 6, 2017.

23. Zou G. A modified Poisson regression approach to prospective studies with binary data. Am J Epidemiol. 2004;159(7):702-06.

24. Zou GY, Donner A. Extension of the modified Poisson regression model to prospective studies with correlated binary data. Stat Methods Med Res. 2013;22(6):661-70.

25. Harashima S, Nishimura A, Ikeda K, Wang Y, Liu Y, Inagaki N. Once daily self-monitoring of blood glucose (SMBG) improves glycemic control in oral hypoglycemic agents (OHA)-treated diabetes: SMBG-OHA follow-up study. J Diabetes Sci Technol. 2015;10(2):378-82.

26. Xie Y, Agiro A, Bowman K, DeVries A. Leveraging benefit design for better diabetes self-management and HbAlc control. Am J Manag Care. In press.

27. Adams AS, Mah C, Soumerai SB, Zhang F, Barton MB, Ross-Degnan D. Barriers to self-monitoring of blood glucose among adults with diabetes in an HMO: a cross sectional study. BMC Health Serv Res. 2003;3(1):6. 
APPENDIX Codes for Diabetes Diagnosis, Insulin, Comorbidity, and Metabolic Disorder Medications

\begin{tabular}{|c|c|c|c|}
\hline Description & ICD-9-CM Diagnosis Codes & GPI Codes & HCPCS \\
\hline Diabetes diagnosis & $\begin{array}{l}250 . x x, 357.2 x, 362.0 x, 366.41 \\
648.0 x\end{array}$ & & \\
\hline Oral antidiabetic drug medication & & $\begin{array}{l}2750 x, 2715 x, 2799 x, 2710 x, 2728 x \\
2717,2755 x, 2720 x, 2760 x\end{array}$ & \\
\hline Diabetic testing strips & & $\begin{array}{l}94100030006100,94100030009800, \\
94100030006000\end{array}$ & \\
\hline Type 1 diabetes diagnosis & $250 . x 1,250 . x 3, V 53.91$ & $2710 x$ & E0784, J1817 \\
\hline \multicolumn{4}{|l|}{ Insulins } \\
\hline Basal & & $\begin{array}{l}27104003 x, 27104006 x, 27101020 x, \\
27101040 x, 27102040 x, 27103020 x, \\
27103040 x, 27104020 x, 27104030 x, \\
27101050 x, 27101030 x, 27102030 x, \\
27102050 x, 27103030 x, 27104050 x, \\
27102020 x\end{array}$ & \\
\hline Bolus & & $\begin{array}{l}27104005 x, 27104002 x, 27104004 x \\
27101010 x, 27101060 x, 27102010 x \\
27102060 x, 27103010 x, 27103060 x, \\
27104010 x, 27104015 x\end{array}$ & \\
\hline Premixed & & $\begin{array}{l}27104080 x, 27104070 x, 27103070 x, \\
27104090 x\end{array}$ & \\
\hline \multicolumn{4}{|l|}{ Comorbidity } \\
\hline Cardiac vascular disease & $410 . x x-414 . x x, 429.2 x$ & & \\
\hline Dyslipidemia & 272.xx & & \\
\hline Hypertension & 401.xx-404.xx & & \\
\hline \multicolumn{4}{|l|}{ Metabolic disorder medications } \\
\hline Cardiovascular disease & & $\begin{array}{l}8560 x, 3210 x, 8310 x, 8320 x, 8330 x \\
8333 x, 8337 x, 3940 x, 8520 x, 8515 x \\
6410 x, 6499 x\end{array}$ & \\
\hline Dyslipidemia & & $\begin{array}{l}\text { 3910x, 3920x, 3930x, 3940x, 3945x, } \\
\text { 3950x, 3999x }\end{array}$ & \\
\hline Hypertension & & $\begin{array}{l}3610 x, 3615 x, 3617 x, 3620 x, 3625 x \\
3630 x, 3640 x, 3660 x, 3699 x\end{array}$ & \\
\hline
\end{tabular}

